\title{
Synthesis of New Porous Natural Membranes with Nanoparticles Used in Pollute Gas Removal From Petroleum Industries
}

\author{
Rasha Gharib Ahmed ${ }^{1,2}$, Kaouther AL-Habib Belgacem ${ }^{1,3}$, \& Hala Mohamed Abo- Dief ${ }^{1,4}$ \\ ${ }^{1}$ Chemistry Department, Faculty of Science, Taif University, Taif, Kingdom of Saudi Arabia \\ ${ }^{2}$ Chemistry Department, Suez Canal University, Egypt \\ ${ }^{3}$ LACReSNE Laboratory, Chemistry Department, Faculty of Sciences of Bizerte, Carthage University, Tunisia \\ ${ }^{4}$ Egyptian Petroleum Research Institute, Nasr City 11727, Cairo, Egypt \\ Correspondence: Kaouther AL-Habib Belgacem, Chemistry Department, Faculty of Science, Taif University, \\ Taif, Kingdom of Saudi Arabia. Email: kaoutherbelgacem.fsm@gmail.com
}

Received: July 22, 2017

doi:10.5539/jmbr.v8n1p159
Accepted: September 14, 2018

Online Published: October 15, 2018

URL: https://doi.org/10.5539/jmbr.v8n1p159

\begin{abstract}
The aim of the present work is to follow the capacity of adsorption of $\mathrm{CO}_{2}$ by natural cellulose nanofibers, extracted from banana peel and mixed with nano-silver. Following initial characterization, the raw material and the isolated sample were investigated by Energy Dispersive Analysis (EDS), X-ray diffraction (XRD); FourierTransformed infrared spectroscopy (FT-IR) and thermal analysis (Hi Res TG). Nitrogen gas adsorption-desorption isotherms of isolated cellulose nanofibers reveal a type I- isotherm, specific to the nano-porous materials. The results of adsorption isotherms of $\mathrm{CO}_{2}$ at $304 \mathrm{~K}$ showed that the extracted sample exhibit an adsorption capacity of $12 \mathrm{mmol} / \mathrm{g}$ of $\mathrm{CO}_{2}$.
\end{abstract}

Keywords: Cellulose, natural nanomaterials, porous, adsorption

\section{Introduction}

New materials obtained from natural, low-cost and renewable resources have seen significant attention to the materials scientists with environmental friendliness (Abraham et al., 2011). The materials isolated from the renewable bio-resources could be the alternative of petroleum based synthetic products due to their advantages of, easy availability, environmental friendly, nontoxicity renewability and relatively low cost .In this sense, plant fibers, which are a primary source of natural fibers, constitute rich sources of cellulose, the principal component of plant cell walls (Lavoine et al.,2012). Generally, the nanofiber domains referred to as nanocellulose are a favorable basic material for novel bio based composites due to their, stiffness, high mechanical strength, low thermal expansion, large surface area, optical transparency, low toxicity, renewability, low cost and biodegradability (Anirudhan et al., 2015).

Recently, cellulose nanofibers have become the topic of many researchers, due to their application in several domains: in the biomedical field (Cherian et al., 2011; Klemm et al., 2006), as reinforcement element in nanocomposites (Kaushik et al., 2010; Khalil et al., 2012), as electronic papers (Shah et al. 2004). Especially, the utilization of nano-reinforcements in the polymer matrix improve matrix properties as compared with the neat polymer and micron (filled, sized) composites based on the same fibers(Lee et al., 2009).Thus, there has been increasing interest in testing the possibilities of using cellulose-based nanofibers as reinforcing elements.

Besides various methods to produce cellulose nanoparticles, their extraction consisted of three steps: (1) pretreatment of initial materials, (2) hydrolysis and (3) mechanical treatment (Sun, 2004). During the process conditions the morphological properties of the nanoparticles is affected, thereby influencing how they execute as reinforcement material in composites (Rosa et al., 2010). Banana is one of the most popular fruits and its cultivation is very diffuse in most tropical countries (Teixeira et al., 2011). The industrialization produces and process of banana cultivation have a massive amount of cellulose-rich residues and the utilization of this biomass help to minimize the environmental pollution and increase value to the cellulose byproduct. In this context, research including this fruit and studding sustainable development has been encouraged the banana peel is a potential source of cellulosic fiber. A natural material which has newly found applications in the production of nanomaterials (Elanthikkal et al., 2010). 
The aim of this study firstly, is to prepare natural cellulose nanofibers from the banana peel, named CNF, through chemical process. Further the isolated cellulose nanofibers were mixed with nano silver (1\%), namely CNF-Ag, to reinforce the efficiency of the prepared cellulose nanofibers. For this purpose, nitrogen isotherms at $77 \mathrm{~K}$ and adsorption isotherm of $\mathrm{CO}_{2}$ at $307 \mathrm{~K}$ analysis were used.

\section{Materials}

The raw material, Bran, was obtained from the peel of banana, mature green ,and was not submitted to any pretreatment. The chemicals(Nano silver, potassium hydroxide, potassium metabisulfite, sodium hypochlorite, sulfuric acid ,acetic acid, and ethanol) utilized in this work were supplied from Asseel-Trading-Est. These chemicals were pure and used without any purification.

- Preparation of Bran

After washing and peeling bananas, the peels were immediately immersed in potassium metabisulfite solution $(1 \% \mathrm{w} / \mathrm{v})$ for $24 \mathrm{~h}$, to inhibit oxidation. Then, the rinsed peels were dried in an oven at $70^{\circ} \mathrm{C}$ for $24 \mathrm{~h}$. After that, the material was ground in a knife mill (model-Lambart-MA201) to remove lipid fractions, the raw material was washed with ethanol and dried again in the same condition, next sieved through a 200 US mesh to eliminate the larger particles. Finely the resulting produce was stored at $5^{\circ} \mathrm{C}$ in a sealed container. The yield of the bran was $55 \%$.

- Extraction of purified natural cellulose nanofibers (CNF)

Cellulose nanofibers, CNF, were extracted from the banana peel bran through the chemical treatment (Zuluaga et al., 2009), this process eliminates non-cellulosic components such as hemicelluloses, lignin and pectins. In the beginning, the bran was treated with an alkaline solution of $5 \% \mathrm{w} / \mathrm{v} \mathrm{KOH} \mathrm{1:20} \mathrm{(bran/solution)} \mathrm{at} \mathrm{room}$ temperature under stirring, which should solubilize the hemicelluloses and the pectin. The substrate was neutralized with alkaline or acid solution (5\% KOH or $10 \%$ acetic acid, respectively) and was submitted to successive washings with distilled water followed by centrifugation out at $8000 \mathrm{rpm}$ for $30 \mathrm{~min}$ until neutral $\mathrm{pH}$ was reached. Thereafter, the insoluble substrate was delignified with $\mathrm{NaClO}_{2} 1 \% \mathrm{w} / \mathrm{v}$ at pH 5.0 (adjusted with acetic acid; $10 \% \mathrm{v} / \mathrm{v}$ ) for $1 \mathrm{~h}$, at $70{ }^{\circ} \mathrm{C}$. The bleaching process broke down the phenolic compounds or molecules displaying chromophoric groups in the lignin; it also eliminated the byproducts of such breakdown, the pulp becoming white the resulting material was submitted to the bleaching treatment using $\mathrm{NaClO}_{2}$ again, to ensure effective discoloration. A second alkaline treatment with alkaline solution under the same conditions as in the first step was carried out. In the end, the insoluble produce was treated with acid hydrolysis with a $\mathrm{H}_{2} \mathrm{SO}_{4}$ $(1 \% \mathrm{v} / \mathrm{v})$ solution for $1 \mathrm{~h}$ at $80{ }^{\circ} \mathrm{C}$ hydrolyze amorphous cellulose and to remove mineral traces, providing the required nanofibers. The insoluble residue was neutralized with acid solution or alkaline $(10 \%$ acetic acid or $5 \%$ $\mathrm{KOH}$ ), depending on the $\mathrm{pH}$, extensively washed with deionized water, and centrifuged, until neutral $\mathrm{pH}$ was reached, After each step of the chemical treatment. The final product was diluted with deionized water and stored in a sealed container at $4{ }^{\circ} \mathrm{C}$.

\section{- Preparation of CNF-Ag}

The suspension isolated cellulose nanofiber, CNF, was mixed with nano-silver (1\%) under stirring at room temperature for $8 \mathrm{~h}$. The resulting $\mathrm{CNF}-\mathrm{Ag}$ was stored at $4{ }^{\circ} \mathrm{C}$ in a sealed container.

For the XRD, FTIR, BET and adsorption of $\mathrm{CO} 2$ analyses, 50mg of the nanofiber suspension obtained after the treatment was dried in a freeze-drier.

\section{Instrumentation}

- Energy dispersive X-ray Spectroscopy

EDS is an analytical analysis to identify the elements and elemental composition exist in the compound. The EDS is a Liquid $\mathrm{N}_{2}$ based $30 \mathrm{~mm}$ detector EDAX model. The EDS analyses are integrated properties of the Scanning Electron Microscope.

- Scanning Electron Microscope

The morphology of samples was examined using a (Philips, XI 30) scanning electron microscope (SEM).

- Transmission Electron Microscopy

TEM analysis was used to determine the diameter of samples. Samples suspensions were diluted and plated in the ultrasound for $20 \mathrm{~min}$. The images were obtained using a transmission electron microscope (JEOL 2011 model) and an acceleration voltage of $100 \mathrm{kV}$. 
- X-ray diffraction

Technique using a model INEL X-Ray diffractometer. The measurement were carried out with a cobalt, $\mathrm{Cu}, \mathrm{K} \alpha$ radiation $(\lambda=1.7890 \AA)$.

- $\quad$ Fourier-Transform Infrared Spectroscopy

FT-IR spectra were recorded in 400 to $4000 \mathrm{~cm}^{-1}$ range, using a Fourier transform infrared spectrophotometer, model- Perkin-Elmer. The analyses were carried out by the $\mathrm{KBr}$ pellet process.

- Thermal Analysis

Hi Res Thermogrametric measurements were carried out on TA instruments, Q500, apparatus, conducted under argon flow with a linear heating rate of $5 \mathrm{Kmin}^{-1}$.

- Adsorption manometry

The nitrogen isotherms at $77 \mathrm{~K}$ were obtained with, ASAP 2010 (France) a commercial manometric device, using a point by point procedure of adsorptive introduction. Approximately $50 \mathrm{mg}$ of sample was weighed into the cell and outgassed to a vacuum of $10^{-3}$ mbar up to $130^{\circ} \mathrm{C}$ prior to each adsorption experiment. The surface area was calculated using the BET equation and the pore volume was calculated from the t-plot analysis.

- Gas Adsorption

Adsorption isotherm of $\mathrm{CO}_{2}$ was carried out using Autosorb 1, Quantachrome, instrument. Around $50 \mathrm{mg}$ of sample was packed into sample cell, and degassed for 8 hours at $130^{\circ} \mathrm{C}$ under vacuum until the outgas rate was less than $3.5 \mathrm{mtorr} / \mathrm{minute}$. The temperature of adsorption $(304 \mathrm{~K})$ was equilibrate with a temperature-controlled bath. The degassed sample and sample cell were weighed precisely.

\section{Results and Discussion}

- Chemical analysis

The element composition of the Bran and isolated samples were determined by EDS is given in Figure1.

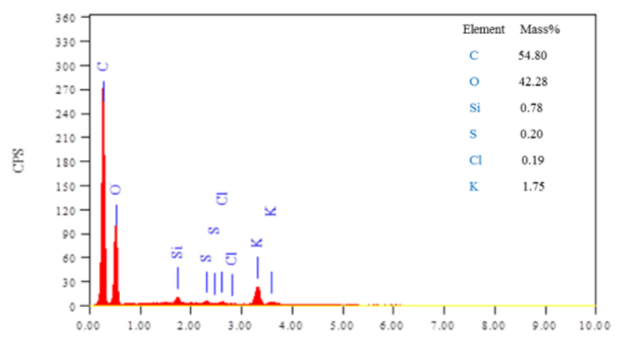

(a)

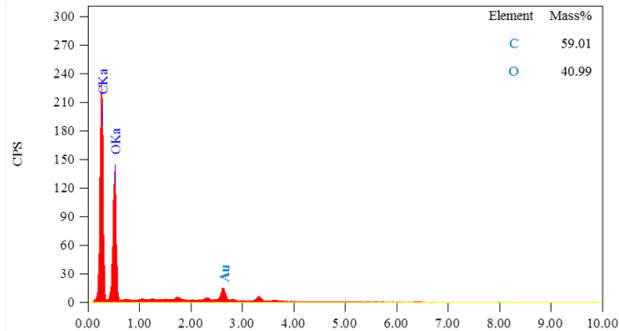

(b)

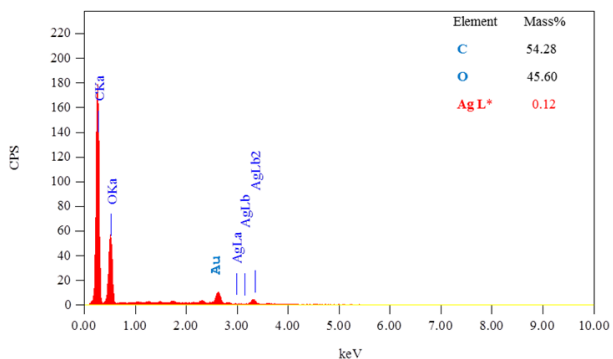

(c)

Figure 1. Energy dispersive x-ray diffraction of (a) Bran, (b) CNF and (c) CNF-Ag

The result of the element analysis indicated high purity of extracted cellulose ( CNF and CNF-Ag), because EDS spectrum of CNF ( Figure 1.b) shows the peaks for carbon and oxygen only, EDS spectrum of CNF-Ag ( Figure 1.c) present only the peaks for carbon, oxygen and silver, Whereas the EDX spectrum of Bran ( Figure 1.a) reveals the peaks for carbon, oxygen and other elements. Also for the comparison of carbon and oxygen percentage, the carbon percentage is higher than the oxygen percentage in the raw material spectrum. So the 
EDS analysis confirmed that the chemicals utilized through the chemical treatment were not detected in the isolated cellulose nanofibers.

\section{- Morphology}

Figure 2. indicates SEM images of the Bran (Figure 2.(a-b)); CNF (Figure 2.(c-d)) and CNF-Ag (Figure 2.(e-f)).The results showed that the initial sample contains heterogeneous surface and some residues. The width of prepared samples was around $20 \mathrm{~nm}$ to $80 \mathrm{~nm}$. Chemical treatment proves structural and chemical changes in the fibers. SEM images of CNF and CNF-Ag showed piecemeal elimination of amorphous components, such as, pectin, hemicelluloses and lignin.
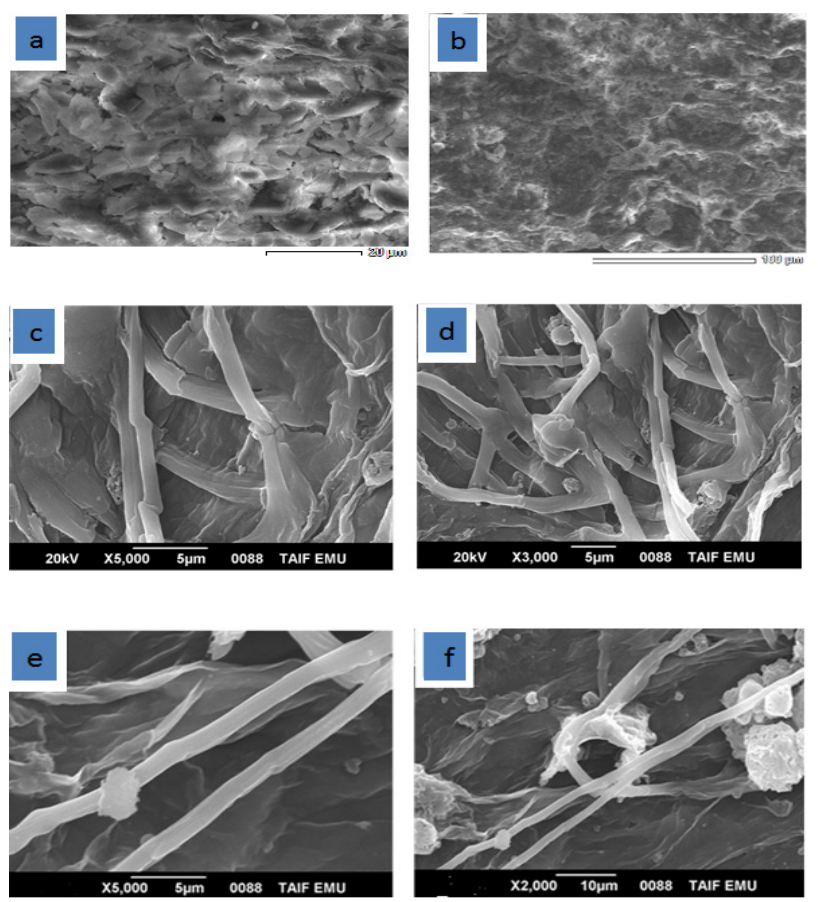

Figure 2. SEM images of Bran at (a) 20um scale and(b) 100um scale; CNF at (c) and(d) 5um scale; CNF-Ag at (e) 5 um scale and(f) 10um scale

TEM images (Figure 3.) of the isolated samples confirmed the presence of nanofibers and suggested also that the chemical treatments removed, hemicelluloses pectin and lignin. Transmission electron microscopy proved that the treatment effectively extracted CNF and CNF-Ag in the nanometer scale.
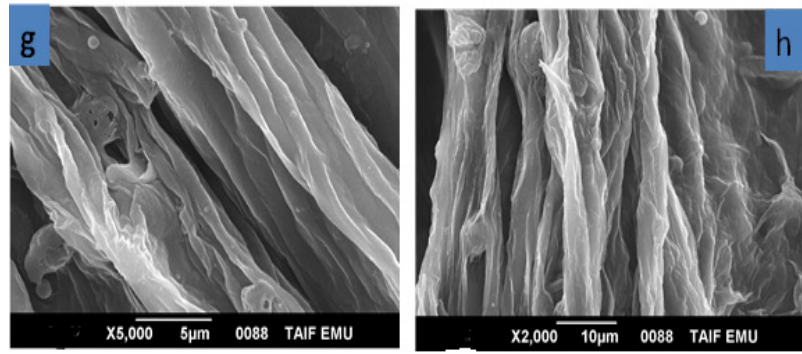

Figure3. TEM images of CNF (g) at 5um scale and CNF-Ag (h) at 10um scale

The analysis of the specific surface area for Bran and synthetized samples was carried out using the BET method (Figure 4.) 


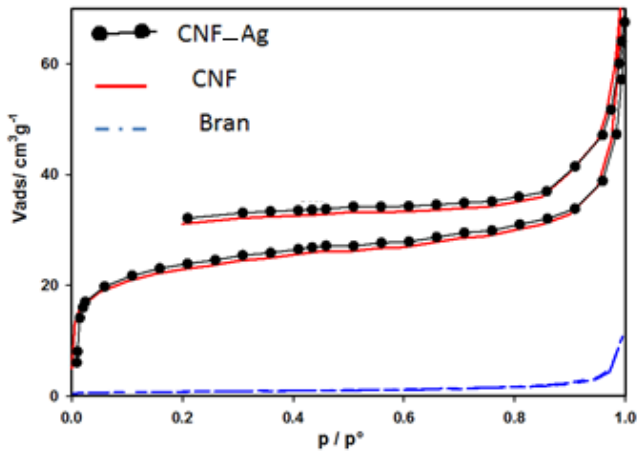

Figure 4. Nitrogen isotherms obtained at $77 \mathrm{~K}$ on samples

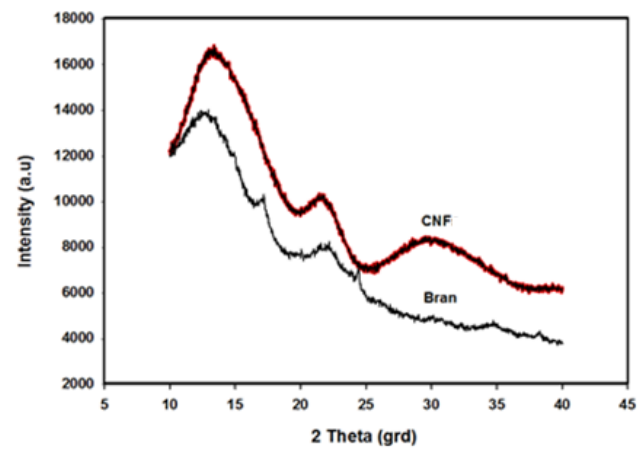

Figure 5. X-ray diffraction results of Bran and CNF

The Bran sample does not present any capacity for $\mathrm{N}_{2}$ sorption while the CNF and CFN-Ag isotherms reveals a type I- isotherm specific to the nano-porous materials. A negligible amount of hysteresis is detected which may be not related to the shape of the pores but rather to the trapping of the gas inside these pores. Nevertheless. very few difference are showed between the CNFs and CNFs-Ag isotherms. This point must be verified by a more detailed study to find the most adequate mixture of composites and isolated cellulose nanofibers. The BET specific surface areas of samples measured by adsorption of nitrogen at $77 \mathrm{~K}$ are:13; 231.3 and $238( \pm 0.2) \mathrm{m}^{2} \mathrm{~g}^{-1}$ for raw material, $\mathrm{CNF}$ and $\mathrm{CNF}-\mathrm{Ag}$ respectively.

\section{- $\quad$ Structure}

The X-ray diffraction of Bran and CNF are given in Figure 5.

The X-ray diffraction pattern of the isolated cellulose nanofibers showed two broad peaks: at $2 \theta=13.41^{\circ}$ and $2 \theta$ $=22^{\circ}$ witch are typical of cellulose I and indicate the higher crystallinity of the nanofibers (Alemdar and Sain 2008). Mulberry branch barks led to similar results (Li et al.,2009). The X-ray diffraction pattern of Bran also showed a less pronounced peak at $2 \theta=22^{\circ}$. Pattern peak at $2 \theta=17^{\circ}$ present in the X-ray diffraction pattern of Bran indicated the presence of starch in the sample. The XRD graphs results revealed that the isolated cellulose nanofibers was more crystalline than the raw material.

The IR spectra of the Bran and the CNF sample were presented in Figure 6 respectively.

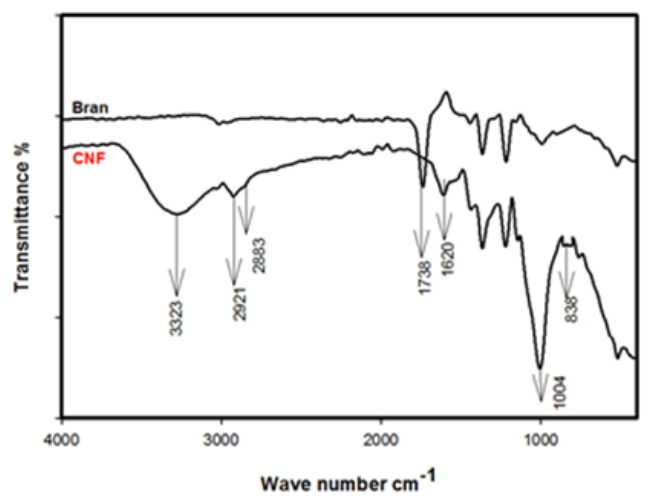

Figure 6. IR spectra of Bran and CNF

The infrared spectra of the two compounds show hydrophobicity of the natural fibers by the very sharp -OH groups stretching in the region of $3650-3000 \mathrm{~cm}^{-1}$. The peak at $3323 \mathrm{~cm}^{-1}$ corresponded to $-\mathrm{OH}$ stretching was attributed to specific intramolecular hydrogen bonds of cellulose II (Yang et al., 2007; Zuluaga et al., 2009). The infrared spectra of raw material displayed a small adsorption band at $2921 \mathrm{~cm}^{-1}$, typical of the stretching vibrations of the $\mathrm{C}-\mathrm{H}$ bonds in hemicelluloses and cellulose. This adsorption bond became more intense in the spectra of CNF samples. This is due to the elimination of lignin. Indeed, the adsorption band assigned to the cellulose $\mathrm{C}-\mathrm{H}$ groups is observed in the $1400-1300 \mathrm{~cm}^{-1}$ region were more intense in the isolated samples as 
compared with the raw material. The shoulder at $1738 \mathrm{~cm}^{-1}$ appearance in the spectrum of the raw material allotted to the acetyl and uronic ester groups of hemicelluloses or to the ester linkage of carboxylic group of the ferulic and p- coumaric acids of lignin (Cherian et al., 2008). This bond disappeared completely from the spectrum of CNF, because the bleaching process eliminate most of the hemicelluloses and lignin from the CNF. Adsorption bands observed near $1730 \mathrm{~cm}^{-1}$ attributed to deformation of the $\mathrm{C}=\mathrm{O}$ groups of xylan (Siqueira et al., 2010), the main component of hemicellulose. The absence of this peak in the spectrum of CNF proved that xylanase acted on the sample during chemical process. The band appeared in the spectrum of the CNF at $1620 \mathrm{~cm}^{-1}$ correspond to absorbed water ; it could also reveal that conjugated carbonyl groups either resulted from carbohydrate oxidation or existed in the polyphenolic structure of lignin. Absorption band appeared at $838 \mathrm{~cm}^{-1}$ in the spectra of the CNF sample and not existed in the spectrum of raw material allotted to typical cellulose structure (Cherian et al., 2008). These results confirmed that the amorphous components was effectively eliminate from the bran sample and permitted CNF extraction.

The High Resolution Thermo gravimetric Analysis of the CNF and CNF-Ag samples obtained under argon flow are given in Figure 7.

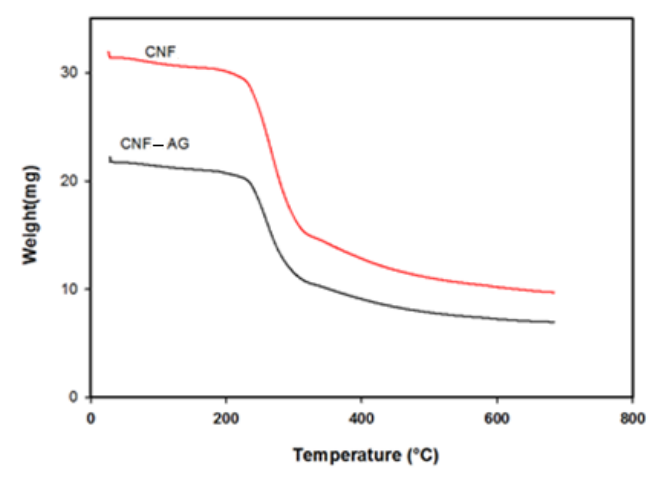

Figure 7. Hi res curves of CNF and CNF-Ag under argon

The Hi Res curves of the nanofiber samples were similar, they show three weight loss domains. The first weight loss between of $50-100{ }^{\circ} \mathrm{C}$, correspond to the moisture evaporation. In the domain ranging from $220-300{ }^{\circ} \mathrm{C}$, the glycosidic linkages of cellulose broke and the hemicellulose depolymerized (Deepa et al., 2011). The broad peak detected from $400-500^{\circ} \mathrm{C}$ refereed to cellulose degradation.

In order to obtain more information on the adsorption proprieties of the isolated cellulose nano fibers mixed with silver, CNF-Ag, an adsorption isotherm of $\mathrm{CO}_{2}$ was carried out.

The adsorption isotherms of $\mathrm{CO}_{2}$ on CNF-Ag sample at $304 \mathrm{~K}$ are presented in Figure. 8

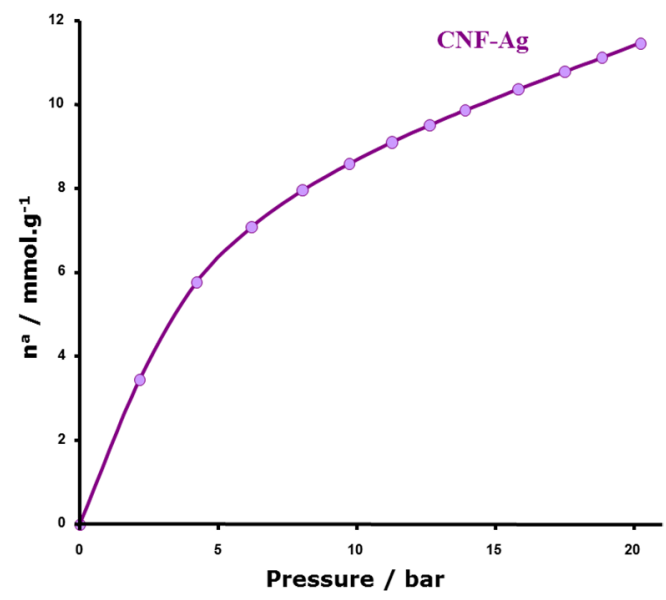

Figure 8. Isotherms of $\mathrm{CO}_{2}$ at $304 \mathrm{~K}$. 
The results showed that the adsorbent CNF-Ag exhibits an adsorption capacity of $12 \mathrm{mmol} / \mathrm{g}^{\circ}$ of $\mathrm{CO}_{2}$ at $304 \mathrm{~K}$, which was much better than that of other conventional adsorbents (e.g Charbon actif Maxsorb, Charbon actif NORIT R1, Zeolithe 13X,...).

\section{Conclusion}

This work present a new concept to utilize a natural nanofibers cellulose as an adsorbent to store $\mathrm{CO}_{2}$. In fact, firstly the nanofibers cellulose were extracted from banana peel through chemical treatment. Then, to highlight its efficiency, the prepared cellulose nanofibers was mixed with nano-silver.

- Purity, size and properties of isolated nanofibres cellulose were determinate by EDS- TEM- SEMXRD. and FTIR measurements.

- Nitrogen isotherms at $77 \mathrm{~K}$ revealed that the prepared cellulose nanofibers exhibit a type I adsorptiondesorption and a surface area.

- A according to the results of adsorption isotherms of $\mathrm{CO}_{2}$ under $304 \mathrm{~K}$, the synthesized cellulose nanofibers mixed with nanosilver indicate an adsorption capacity of $12 \mathrm{mmol} / \mathrm{g}$ of $\mathrm{CO}_{2}$, which was much better than that of other conventional adsorbents.

In conclusion, we successfully extracted an adsorbent cellulose nanofibers from banana peels, an agroindrustrial residue, as natural, low-cost and renewable source of nanofibers.

A next study will be focusing to investigate the capacity of these natural new absorbents to store $\mathrm{H}_{2} \mathrm{~S}$, petroleum gas polluted to the environment.

\section{Acknowledgement}

The authors gratefully acknowledge Taif University and the Ministry of Higher Education, Saudi Arabia for sponsoring and generous supporting this research under the project No (1-438-5911).

\section{References}

Abraham, E., Deepa, B., Pothan, L. A., Jacob, M., Thomas, S., Cvelbar, U., \& Anandjiwala, R. (2011). Extraction of nanocellulose fibrils from lignocellulosic fibres: A novel approach. Carbohydrate Polymers, 86(4), 1468-1475.

Alemdar, A., \& Sain, M. (2008). Biocomposites from wheat straw nanofibers: morphology, thermal and mechanical properties. Composites Science and Technology, 68(2), 557-565.

Anirudhan, T. S., Gopal, S. S., \& Rejeena, S. R. (2015). Synthesis and characterization of poly (ethyleneimine)-modified poly (acrylic acid)-grafted nanocellulose/nanobentonite superabsorbent hydrogel for the selective recovery of $\beta$-casein from aqueous solutions. International Journal of Polymeric Materials and Polymeric Biomaterials, 64(15), 772-784.

Cherian, B. M., Leão, A. L., de Souza, S. F., Costa, L. M. M., de Olyveira, G. M., Kottaisamy, M., ... Thomas, S. (2011). Cellulose nanocomposites with nanofibres isolated from pineapple leaf fibers for medical applications. Carbohydrate Polymers, 86(4), 1790-1798.

Cherian, B. M., Pothan, L. A., Nguyen-Chung, T., Mennig, G., Kottaisamy, M., \& Thomas, S. (2008). A novel method for the synthesis of cellulose nanofibril whiskers from banana fibers and characterization. Journal of agricultural and food chemistry, 56(14), 5617-5627.

de Morais Teixeira, E., Bondancia, T. J., Teodoro, K. B. R., Correa, A. C., Marconcini, J. M., \& Mattoso, L. H. C. (2011). Sugarcane bagasse whiskers: extraction and characterizations. Industrial Crops and Products, 33(1), 63-66.

Deepa, B., Abraham, E., Cherian, B. M., Bismarck, A., Blaker, J. J., Pothan, L. A., ... \& Kottaisamy, M. (2011). Structure, morphology and thermal characteristics of banana nano fibers obtained by steam explosion. Bioresource Technology, 102(2), 1988-1997.

Elanthikkal, S., Gopalakrishnapanicker, U., Varghese, S., \& Guthrie, J. T. (2010). Cellulose microfibres produced from banana plant wastes: Isolation and characterization. Carbohydrate polymers, 80(3), 852-859.

Kaushik, A., Singh, M., \& Verma, G. (2010). Green nanocomposites based on thermoplastic starch and steam exploded cellulose nanofibrils from wheat straw. Carbohydrate Polymers, 82(2), 337-345.

Khalil, H. A., Bhat, A. H., \& Yusra, A. I. (2012). Green composites from sustainable cellulose nanofibrils: A review. Carbohydrate Polymers, 87(2), 963-979. 
Klemm, D., Schumann, D., Kramer, F., Heßler, N., Hornung, M., Schmauder, H. P., \& Marsch, S. (2006). Nanocelluloses as innovative polymers in research and application. In Polysaccharides Ii (pp. 49-96). Springer, Berlin, Heidelberg.

Lavoine, N., Desloges, I., Dufresne, A., \& Bras, J. (2012). Microfibrillated cellulose-Its barrier properties and applications in cellulosic materials: A review. Carbohydrate polymers, 90(2), 735-764.

Lee, K. Y., Blaker, J. J., \& Bismarck, A. (2009). Surface functionalisation of bacterial cellulose as the route to produce green polylactide nanocomposites with improved properties. Composites Science and Technology, 69(15-16), 2724-2733.

Li, R., Fei, J., Cai, Y., Li, Y., Feng, J., \& Yao, J. (2009). Cellulose whiskers extracted from mulberry: A novel biomass production. Carbohydrate Polymers, 76(1), 94-99.

Pelissari, F. M., do Amaral Sobral, P. J., \& Menegalli, F. C. (2014). Isolation and characterization of cellulose nanofibers from banana peels. Cellulose, 21(1), 417-432.

Rosa, M. F., Medeiros, E. S., Malmonge, J. A., Gregorski, K. S., Wood, D. F., Mattoso, L. H. C., ... \& Imam, S. H. (2010). Cellulose nanowhiskers from coconut husk fibers: Effect of preparation conditions on their thermal and morphological behavior. Carbohydrate Polymers, 81(1), 83-92.

Shah, J., \& Brown, R. M. (2005). Towards electronic paper displays made from microbial cellulose. Applied microbiology and biotechnology, 66(4), 352-355.

Siqueira, G., Bras, J., \& Dufresne, A. (2010). Luffa cylindrica as a lignocellulosic source of fiber, microfibrillated cellulose and cellulose nanocrystals. BioResources, 5(2), 727-740.

Sun, J. X., Sun, X. F., Zhao, H., \& Sun, R. C. (2004). Isolation and characterization of cellulose from sugarcane bagasse. Polymer degradation and stability, 84(2), 331-339.

Yang, H., Yan, R., Chen, H., Lee, D. H., \& Zheng, C. (2007). Characteristics of hemicellulose, cellulose and lignin pyrolysis. Fuel, 86(12-13), 1781-1788.

Zuluaga, R., Putaux, J. L., Cruz, J., Vélez, J., Mondragon, I., \& Gañán, P. (2009). Cellulose microfibrils from banana rachis: Effect of alkaline treatments on structural and morphological features. Carbohydrate Polymers, 76(1), 51-59.

\section{Copyrights}

Copyright for this article is retained by the author(s), with first publication rights granted to the journal.

This is an open-access article distributed under the terms and conditions of the Creative Commons Attribution license (http://creativecommons.org/licenses/by/4.0/). 